\title{
THE TREATMENT OF FRACTURES OF THE SHAFT OF THE FEMUR USING NYLON CERCLAGE
}

\author{
A. J. PARTRIDGE + , P. E. L. EVANS \\ From St Thomas' Hospital, London, and St Richard's Hospital, Chichester
}

\begin{abstract}
A new method of treating older patients with spiral or comminuted fractures of the femoral shaft is described using a combination of multiple nylon cerclage straps and intramedullary nailing. The operative technique is outlined and the results presented. The operation provides a satisfactory alternative to conservative treatment on traction. With modifications the method can also be used for fractures below a prosthesis.
\end{abstract}

Fixation of spiral fractures by cerclage with wires or metallic bands has been practised for over two centuries (Venable and Stuck 1947). In 1913 Parham introduced his famous band (Parham 1913-4). This wide steel band, closely applied round the bone, interfered with the cortical circulation. Poor results brought the method into disrepute.

A new type of cerclage, consisting of self-locking nylon straps, was introduced by Partridge (1976), and has since then been on restricted trial in the United Kingdom. A series of projections on the inner surface of the straps safeguards the cortical circulation. Among the uses of these straps has been the fixation of spiral or comminuted fractures of the femoral shaft in patients over the age of 60 years. The operation was introduced as an alternative to conservative treatment on traction, which carries significant medical risks in this age group. At first the straps were used alone, but it soon became apparent that such fixation failed to control angulation at the fracture site, and that the addition of an intramedullary nail was required to achieve stable fixation. This paper describes the results of nylon cerclage in two series of fractures: primary fractures of an otherwise normal femur and those in the vicinity of a hip prosthesis.

\section{MATERIALS AND METHODS}

Primary fractures. Between June 1976 and September 1979, 29 patients over the age of 60 years with spiral or comminuted fractures of the femoral shaft were treated by nylon cerclage and intramedullary nailing. Eighteen were operated on by one of the authors (AJP), the remainder being treated by 10 other surgeons. Küntscher nails (24 cases), AO (one case) or Zickel nails (four cases) were used according to the level of the fracture and the preference of the surgeon. In 70 per cent of cases the fracture was in the upper third of the femur, while comminution was present in 50 per cent. The age, and sex distribution of the patients is shown in Figure 1.

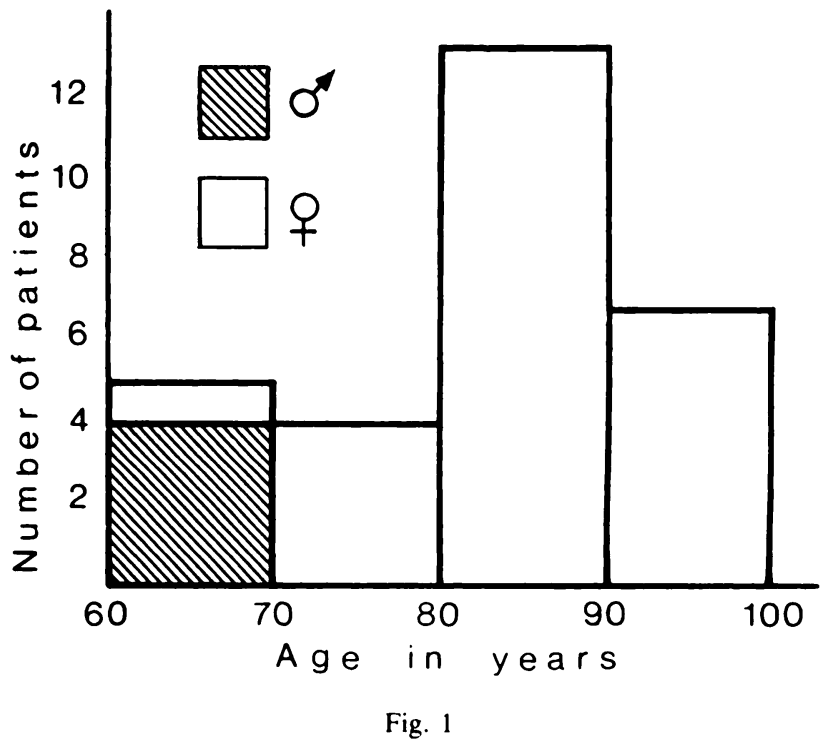

Histogram of the age and sex distribution of patients with a primary fracture.

Below a hip prosthesis. Between January 1977 and February 1980, 19 patients were treated by cerclage combined with longitudinal support. Twelve of these patients were too frail for an extensive operation; in them straps and plates were used. Seven patients who were relatively fit had the prosthesis and cement removed, a long-stemmed prosthesis inserted and the straps applied. In addition, 10 earlier patients had been treated by cerclage alone, but this method has now been abandoned.

A. J. Partridge, FRCS, deceased.

P. E. L. Evans, FRCS, MSc, Orthopaedic Department, Bronx Municipal Hospital, Bronx, New York, NY 10461. USA.

Requests for reprints should be sent to Mr P. E. L. Evans.

(1) 1982 British Editorial Society of Bone and Joint Surgery 0301-620X/82/2040-0210\$2.00 


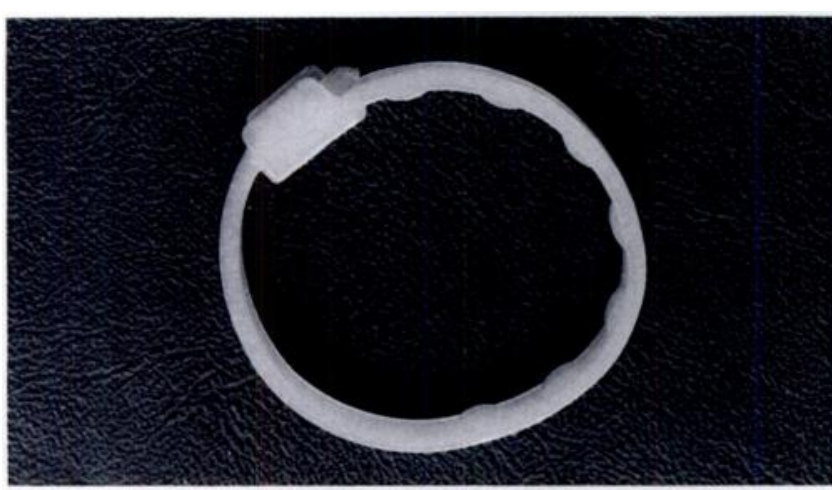

Fig. 2

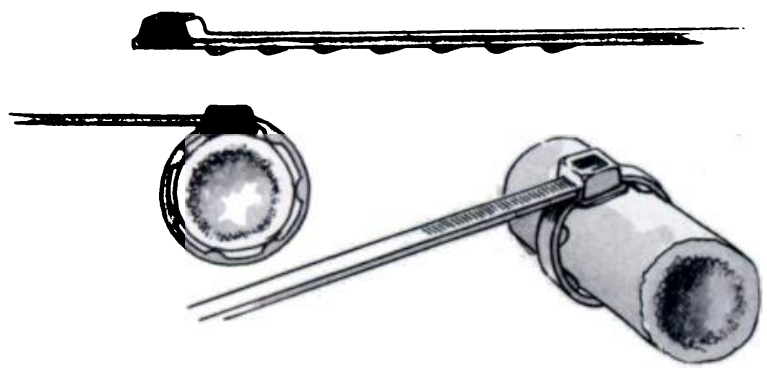

Fig. 3

Photograph and diagrams of the Partridge strap showing the nylon band with internal projections and the self-locking mechanism.

The nylon straps are illustrated in Figures 2 and 3 , the introducer in Figure 4 and the tightening "gun" in Figure 5.

Operative technique. The fracture is exposed with the patient lying in the lateral position. Comminuted fragments are reattached with nylon straps or bone clamps and the femoral canal reamed to accept a nail of between 9 and 12 millimetres in diameter. Only minimal reaming is needed in osteoporotic bone. Larger nails are avoided to minimise loss of reduction during insertion. The fracture is then held reduced with clamps while the nail is introduced. Finally the clamps are replaced by straps and the wound closed using suction drainage. Between three and eight straps are commonly used. Care is taken not to leave the upper end of the nail protruding unduly.

Nylon cerclage straps can also be used for patients in whom the femur has fractured below a prosthesis. An intramedullary nail cannot be used but support in the long axis of the bone can be provided either by special plates, or by the use of a long-stemmed prosthesis.

The special plates are made of nylon and conform to the shape of the bone. They contain slots through which the cerclage straps are passed (Fig. 6). Metal spikes on the inner surface of the plates grip the bone and hold the plates away from it. They are quicker to apply than conventional plates and screws, and hold osteoporotic bone better. At least two plates are used, one on the anterior and one on the lateral surface; they must span the fracture and are best staggered as shown in Figure 7.
It is useful to assemble the plates and straps before applying them.

Sometimes the patient with a prosthesis is fit for a more extensive procedure. If so, the femoral prosthesis and cement are removed and a long-stemmed prosthesis is inserted. Cerclage straps are applied, but the nylon plates are not needed.

After-care. If, after fixation, the fracture remains unstable on rotation, skin traction is applied for three weeks after operation.

Providing the femur has longitudinal support from a Küntscher nail or long-stemmed prosthesis, then the

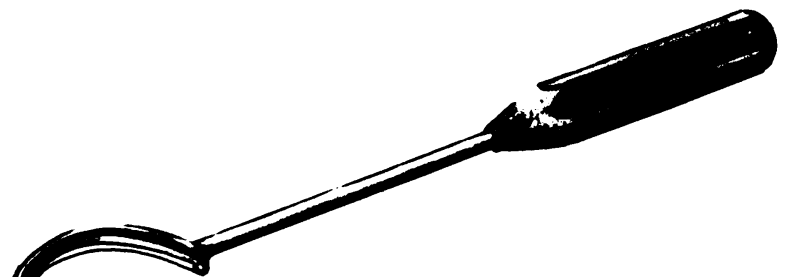

Fig. 4

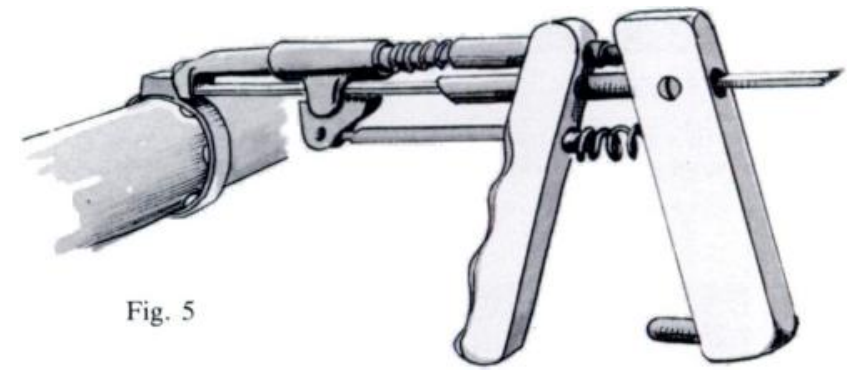

Figure 4-The introducer. Figure 5-The tightening "gun".

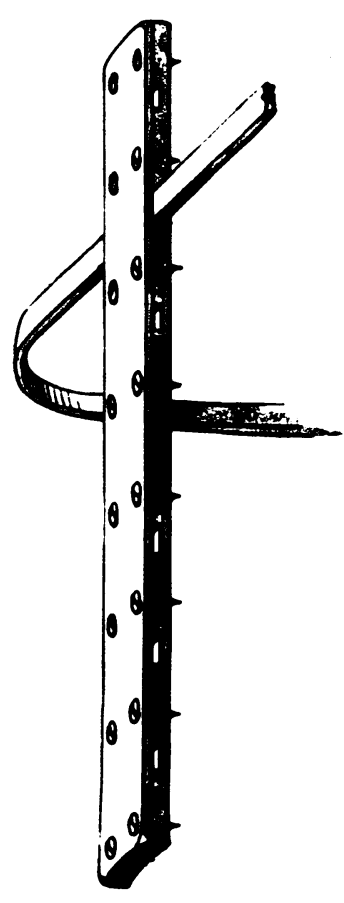

Fig. 6

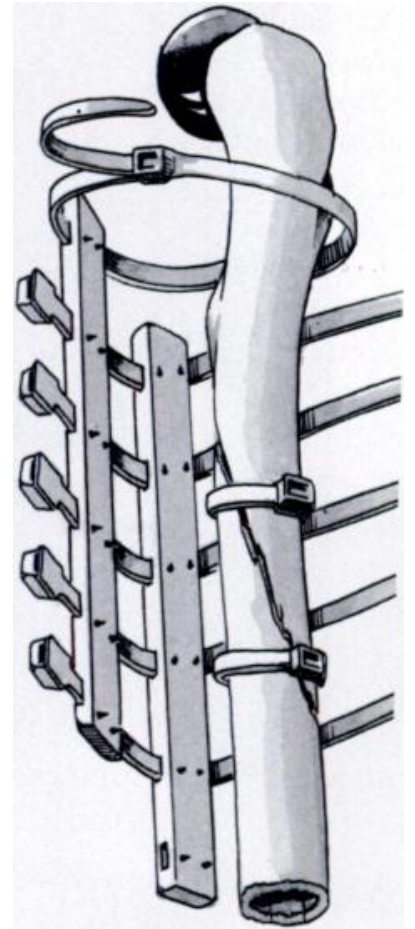

Fig. 7
Figure 6-Diagram to show the straps passed through the slots in the plate. Figure 7-Two plates are used and are staggered. 


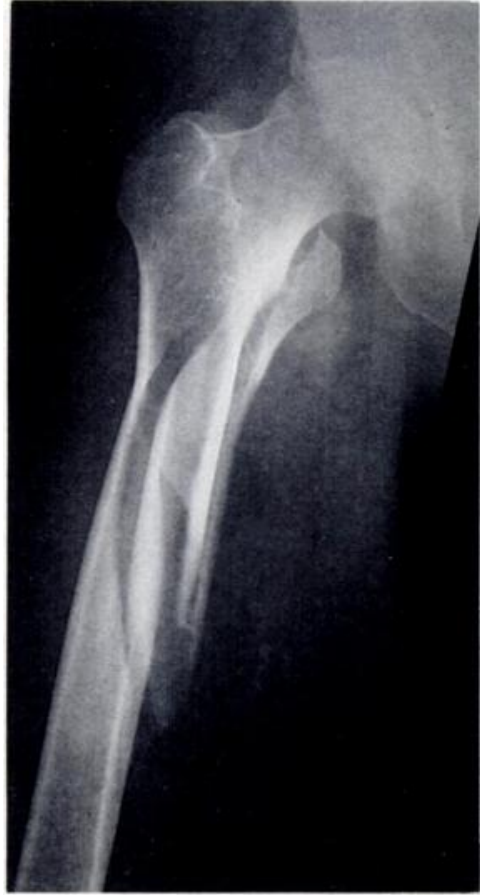

Fig. 8

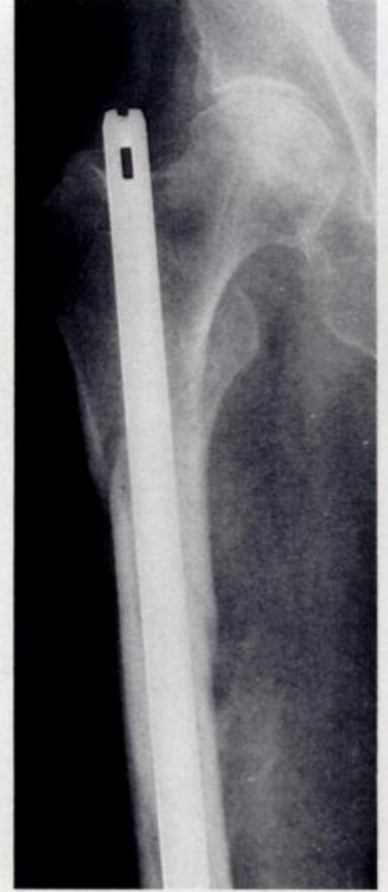

Fig. 9

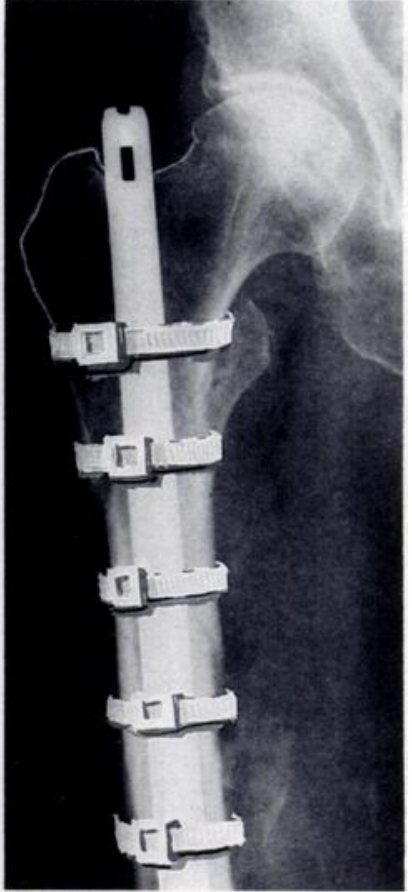

Fig. 10

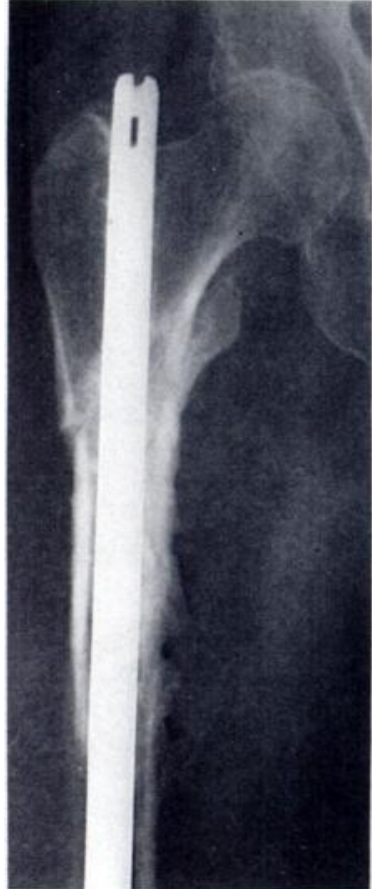

Fig. 11

Treatment of a spiral fracture of the femur in a 67-year-old man. Figure 8-Initial radiograph. Figure 9-Twelve weeks after fixation with a Küntscher nail and five nylon straps (radiolucent). Figure 10-An artist's impression showing the straps in position. Figure $11-O n e$ year after operation.

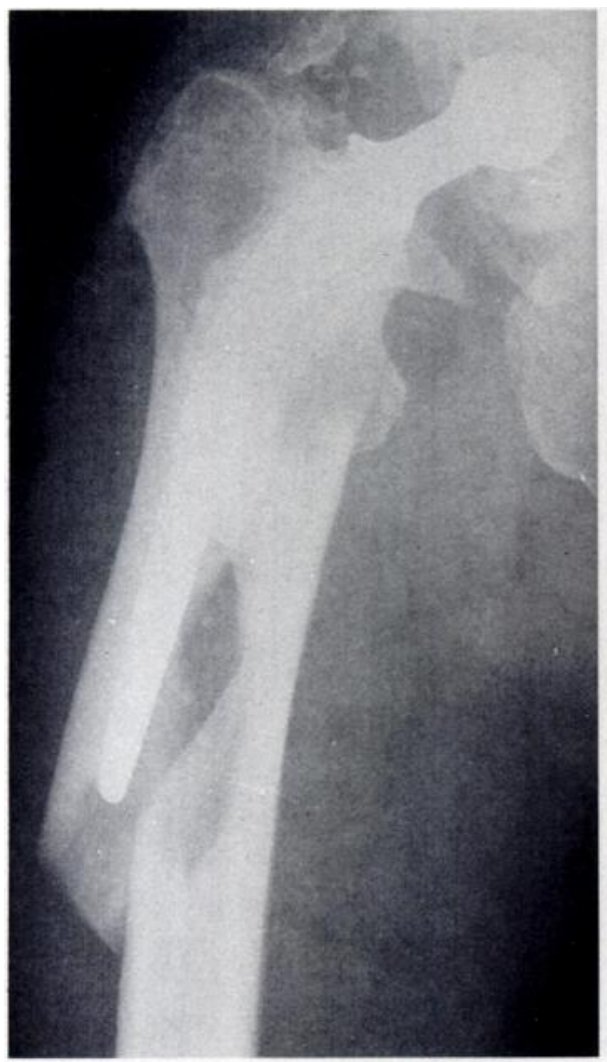

Fig. 12

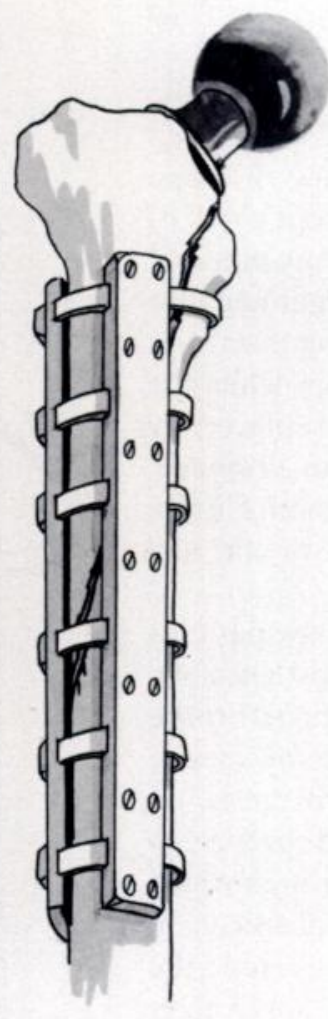

Fig. 13

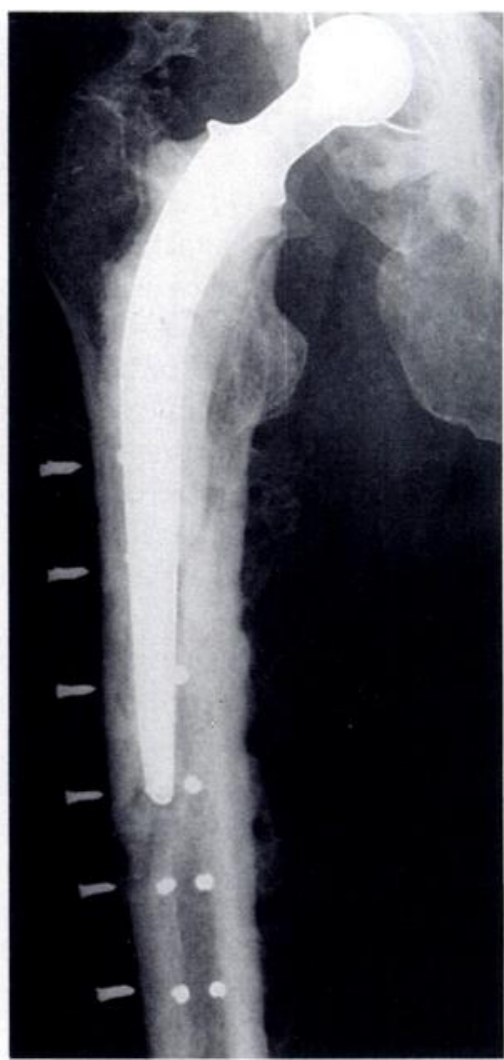

Fig. 14

Fracture in the vicinity of a prosthesis in a fit 76-year-old man. Figure 12-Radiograph on admission. Figure 13-Plan of the operation. Figure 14-Radiograph at one year. 
Table I. The Charnley numerical classification

1. Bedridden or only able to walk a few yards with two sticks or crutches.

2. Able to walk for only a short time or distance with or without sticks.

3. Walking ability limited to less than one hour with a stick, but able to stand for long periods.

4. Requires a stick, but able to walk long distances.

5. Walks without a stick, but has a limp.

6. Walks normally.

patient is allowed up and no special precautions are needed; graduated weight-bearing may be permitted. If only plates and straps have been used, the femur lacks adequate longitudinal support; even straight-leg raising is dangerous and may lead to angulation. The vertical position is safer and the patient should be got up non-weight-bearing as soon as possible.

Review. The case notes and radiographs of all patients have been reviewed. All those still alive were reexamined. Walking ability was graded according to Charnley's numerical classification (1972) (Table I). Shortening of the femur and the range of movement at the hip and knee were also recorded. The follow-up period averaged two years (range one to four years).

\section{ILLUSTRATIVE CASES}

Case 1. A 67-year-old man fell in September 1978 and sustained a spiral fracture of the upper third of his right femur (Fig. 8). At operation the fracture was reduced and held with a Küntscher nail (Fig. 9) and five nylon straps, which, since they are radiolucent, have been drawn in Figure 10. The fracture was stable after fixation. The patient was mobilised non-weight-bearing five days after operation and went home two weeks later. Radiography at 12 weeks showed callus formation. He regained excellent function with full hip and knee movement, and one centimetre of shortening. Figure 11 shows the radiological appearance at one year.

Case 2. A fit man age 76, whose hip had been replaced 18 months earlier, sustained the fracture shown in Figure 12. Somewhat unusually the prosthesis was not loose. Consequently it was not replaced. The fracture was secured with nylon plates (in this instance not staggered) and straps (Fig. 13). He was got up the next day using crutches, but taking very little weight. He went home on the seventeenth day and Figure 14 shows the fracture united at one year.

\section{RESULTS}

Primary fractures. The average time spent in hospital was 6.6 weeks. Five patients required skin traction to control rotation; it was used for an average period of three weeks.

Of the 29 patients in this study, five (whose age averaged 91 years) died of medical complications within one month of operation. Eleven other patients (whose age averaged 81 years) died during the follow-up period: two from carcinomatosis following their pathological fracture and the remainder from causes unrelated to their original injury or operation.
Table II Results based on the Charnley numerical classification

\begin{tabular}{|c|c|c|c|}
\hline $\begin{array}{c}\text { Age range } \\
\text { (years) }\end{array}$ & $\begin{array}{c}\text { Number of } \\
\text { patients reviewed }\end{array}$ & $\begin{array}{c}\text { Average score } \\
\text { before operation }\end{array}$ & $\begin{array}{c}\text { Average score } \\
\text { after operation }\end{array}$ \\
\hline $60-69$ & 4 & 5.5 & 4.8 \\
$70-79$ & 2 & 4.5 & 4.0 \\
$80-89$ & 4 & 2.3 & 1.8 \\
$90+$ & 3 & 1.7 & 1.3 \\
\hline
\end{tabular}

All 24 patients who survived the early postoperative period showed radiological evidence of bony union. Callus was normally visible at three to four weeks and union noted at eight to ten weeks.

Thirteen patients remain alive and have been re-examined. Shortening in the operated limb varied from nil to four centimetres with an average of two centimetres. In about 25 per cent of patients the upper end of the nail was palpable as a result of this shortening. No loss of movement at the hip was found. There was an average of 30 per cent loss of flexion at the knee. Retrospective information about walking ability before the injury was compared with the function at the time of review. The results are presented in Table II.

Below a hip prosthesis. Before we realised that cerclage straps alone (without longitudinal support) were unsafe, 10 patients had been treated in this way; three refractured. Although the other seven united, the method is clearly inadequate and has been abandoned. A further 19 patients were treated by cerclage combined with longitudinal support; in all these the fracture united. Of the 12 frail patients treated by straps and plates, two walked unaided, but the remaining 10 needed sticks or a frame, probably because in each case the prosthesis was loose. Of the seven patients who had long-stemmed replacement prostheses inserted, all but one walked unaided.

\section{DISCUSSION}

Much controversy surrounds the use of cerclage for fracture fixation. The technique has been criticised as both biologically and mechanically unsound. Charnley (1961) states that wire cerclage devitalises the underlying cortex and inhibits periosteal callus formation. Studies of bone blood flow show that blood normally flows outwards from the medullary cavity through the cortex (Brookes 1971). Cerclage has the potential to obstruct venous outflow from the cortex, but the extent to which it does so depends on the contact area between the cerclage device and the bone (Albright, Johnson and Saha 1978). The nylon cerclage straps used in this study have small projections on their undersurface which hold the strap slightly away from the bone over most of its circumference, and experimental studies have shown no significant venous obstruction (Brookes 1971; Brookes and Heatley 1980). We could find no clinical evidence in our study of cortical avascularity following the use of 
multiple nylon cerclage and intramedullary nailing. All the fractures united at a normal rate and abundant callus was a regular radiological feature.

We believe that poor results after cerclage fixation arise from a failure to appreciate the mechanical limitations of the technique. Before the present study, six patients with spiral fractures in previously undisturbed femoral shafts were treated by fixation with nylon straps alone. All failed within three weeks due to fracture of the bony spikes. The strength of these spikes in a spiral fracture is considerably less than the strength of the intact tubular bone, and they break when subjected to angulatory stresses. These stresses, caused by the weight of the leg below the fracture, are neutralised by the use of an intramedullary nail or by a long-stemmed prosthesis.

Spiral fractures of the femur are commonly treated by skeletal traction; the patient is usually in bed for 12 weeks or more and, especially in the elderly, this carries appreciable risks. Operative treatment of such fractures by nail-plate devices may fail because the metal readily cuts out of osteoporotic bone. The combination of multiple nylon cerclage and intramedullary nailing has been found to be a satisfactory method of treatment, providing stable fixation and allowing early mobilisation in most cases. The main local complication was shortening of the femur and protrusion of the nail at the upper end. This can be minimised by keeping the patient on traction for three to four weeks if the fracture, after operation, seems unstable, and by ensuring that the nail is not left standing proud of the greater trochanter; in addition, early weight-bearing should, if possible, be avoided.

The operative treatment of fractures in the very elderly entails significant risks which have to be balanced against the dangers of prolonged traction. Nevertheless, it can be seen from the relatively short period of hospital stay and from the walking ability of the surviving patients that the method has given satisfactory results; even those who failed to survive the postoperative period were made more comfortable by their fixation.

Fractures below a hip prosthesis are being encountered with increasing frequency and may be very difficult to treat. In most of our patients the prosthesis was loose before the patient fell, or was loosened by the fracture. In such cases removal of prosthesis and cement, followed by the insertion of a long-stemmed prosthesis and the application of cerclage straps, is a very satisfactory procedure. But if the patient is not fit for so extensive an operation the prosthesis can be left in situ, and the fracture stabilised with nylon plates and straps. Early mobilisation is then possible though, because the prosthesis is loose, sticks or a frame may be needed.

Many people have assisted with this cerclage project and without their help it could not have been accomplished. Mr A. G. Apley appreciated the importance of the subject and made available to us the research facilities of St Thomas' Hospital, London. Howmedica sponsored the project. Extensive research programmes have been carried out by Professor Rhinelander of Los Angeles, formerly of Little Rock, Arkansas, Dr Murray Brookes of Guy's Hospital, London, and Mr Fred Heatley, Director of Orthopaedic Research at St Thomas'. Dr John Shore of the Department of Pathology, Worthing Hospital, gave us great help with pathological specimens. emphasising the extreme degree of osteoporosis present in elderly patients. Ricardo Engineers. Shoreham-by-Sea, suggested nylon straps. Insuloid of Manchester designed the orthopaedic strap and Harwell assisted with plate design. Surgeons from 12 centres have joined in the clinical programme. We are grateful to them all.

\section{REFERENCES}

Albright JA, Johnson TR, Saha S. Effects on blood supply. In: Ghista DN, Roaf R, eds. Orthopaedic mechanics: procedures and devices. London, New York and San Francisco: Academic Press, 1978:181-2.

Brookes M. The blood supply of bone. London: Butterworth, 1971.

Brookes M, Heatley F. An experimental study of nylon cerclage and its effects on fracture repair. In: Uhthoff HK. Stahl E, eds. Current concepts of internal fixation of fractures. Berlin, Heidelberg, New York: Springer-Verlag, 1980:348-54.

Charnley J. The closed treatment of common fractures. 3rd ed. Edinburgh and London: E \& S Livingstone Ltd, 1961:24-6.

Charnley J. The long-term results of low-friction arthroplasty of the hip performed as a primary intervention. J Bone Joint Surg [Br] 1972; 54-B: $61-76$

Parham FW. A new device for the treatment of fractures. N Orleans Med Surg J 1913-4;66:451, 465-7.

Partridge AJ. Nylon straps for internal fixation of bone. Lancet 1976;ii: 1252.

Venable CS, Stuck WG. The early use of metal appliances. The internal fixation of fractures. Oxford: Blackwell Scientific Publications, 1947: Chapter 1. 